\title{
O PANORAMA DOS DIREITOS HUMANOS NO ACESSO A JUSTIÇA PELA VIA DOS DIREITOS SOCIAIS: A JUSTIÇA RESTAURATIVA TRABALHISTA UMA REALIDADE POSSÍVEL?
}

\author{
Jaqueline Beatriz Griebler ${ }^{1}$ \\ Rosane Teresinha Carvalho Porto ${ }^{2}$ \\ Tânia Regina Silva Reckziegel ${ }^{3}$
}

\begin{abstract}
RESUMO
$\mathrm{O}$ artigo possui intuito central, elencar pontos acerca do acesso à Justiça, como tradução de aplicabilidade dos direitos humanos, analisando possibilidade da Justiça Restaurativa (JR) no Direito do Trabalho, tendo como problema duas perguntas centrais: é possível implementar a JR nos conflitos individuais e coletivos de trabalho? Quais limites e possibilidades? Nessa construção, utiliza-se o método hipotético dedutivo, com base em levantamento bibliográfico. Conclui-se ao final, que a JR aplicada na Justiça do Trabalho, é uma interessante ferramenta, que se implementada, garante acesso à Justiça e melhora a prestação de serviços ao cidadão.
\end{abstract}

Palavras-chave: Direitos Humanos; Justiça Restaurativa; Justiça do Trabalho; Acesso à Justiça.

\section{THE PANORAMA OF HUMAN RIGHTS IN ACCESS TO JUSTICE THROUGH SOCIAL RIGHTS: RESTAURATIVE LABOR JUSTICE A POSSIBLE REALITY?}

\begin{abstract}
Article, has a central purpose, to list points about access to Justice, as a translation of the applicability of human rights, analyzing the possibility of Restorative Justice (JR) in Labor Law, having as a problem two central questions: is it possible to implement JR in individual conflicts and work groups? What limits and possibilities? In this construction, the hypothetical deductive method is used, based on a bibliographic survey. We conclude at the end that the JR applied in the Labor Court is an interesting tool, which, if implemented, guarantees access to Justice and improves the provision of services to citizens.
\end{abstract}

\footnotetext{
${ }^{1}$ Mestranda do Programa de Pós-Graduação em Direito - Mestrado em Direitos Humanos da Universidade Regional do Noroeste do Estado do Rio Grande do Sul - UNIJUÍ e bacharel em Direito pela Universidade Regional do Noroeste do Estado do Rio Grande do Sul - UNIJUÍ. Integrante do Grupo de pesquisa Biopolítica e Direitos Humanos (CNPq). E-mail: jaqeline-beatriz@ hotmail.com

${ }^{2}$ Pós-doutoranda em Direito pela Universidade La Salle (RS). Doutora em Direito pela UNISC(RS). Mestre em Direito na área de concentração: Políticas Públicas de Inclusão Social com bolsa da Coordenação de Aperfeiçoamento de Pessoal de Nível Superior - CAPES. Especialização pela PUC/RS em Docência no Ensino Superior. Especialização pela PUC/RS em Nova Educação, Metodologias e foco no aluno. Professora na Universidade Regional do Noroeste do Estado do Rio Grande do Sul - UNIJUÍ, lecionando na graduação em Direito e no Programa de Pós Graduação em Direito - Mestrado e Doutorado. Professora na graduação em direito e na Pós Lato Sensu na UNISC (Universidade de Santa Cruz do Sul). Estuda temáticas voltadas a criança e adolescente, violência, criminologia, gênero, direitos sociais, Acesso à Justiça e Direitos Humanos. Integrante do Grupo de Pesquisa Biopolítica \& Direitos Humanos (CNPq). E-mail: rosane.cp@unijui.edu.br

${ }^{3}$ Mestre em Direitos Sociais e Políticas Públicas pela UNISC. Doutoranda em Ciências Jurídicas pela Universidad del Museo Social, UMSA, Argentina (2019). Conselheira do CNJ - Conselho Nacional de Justiça. Desembargadora do TRT4 - Tribunal Regional do Trabalho da 4. ${ }^{2}$ Região. E-mail: taniasilvareck@gmail.com
}

Rev. Cidadania e Acesso a Justiça | e-ISSN: 2526-026X | Evento Virtual | v. 6 | n. 1 | p. 55-71 | 
Keywords: Human rights; Restorative Justice; Work justice; Access to justice.

\section{INTRODUÇÃO}

O presente artigo tem por objetivos analisar o panorama dos Direitos Humanos no Acesso à Justiça pela via dos Direitos Sociais, bem como os limites e as possibilidades de implementação da Justiça Restaurativa trabalhista; Contextualizar sobre o marco nacional e internacional da Justiça restaurativa: essencialidades, características, princípios e valores; Abordar sobre a Resolução CSTJ n ${ }^{\circ}$ 174, de 30 de setembro de 2016 que dispõe sobre a política judiciária nacional de tratamento adequado das disputas de interesses no âmbito do Poder Judiciário Trabalhista e verificar os limites e as possibilidades da implementação da justiça restaurativa trabalhista no enfrentamento da violação dos direitos sociais como o trabalho escravo contemporâneo, com base na análise crítica das experiências brasileiras com as práticas restaurativas fundadas na Resolução 225 do CNJ/2016;

A Justiça Restaurativa além de ser conjunto de técnicas e práticas de pacificação dos conflitos, significa o sentido amplo de justiça que o cidadão busca nas suas relações sociais e trabalhistas, para a prevalência da equidade, do respeito e do acordo consensual pautado em princípios e valores para a convivência em comunidade.

No Brasil a Justiça Restaurativa por meio da lei n. 12.594/12 do SINASE (Sistema Nacional de Atendimento Socioeducativo) e da Resolução 225 do CNJ/16 tem contribuído para a implementação e o andamento de programas restaurativos nas diversas áreas (do Juizado da Infância e da Juventude, das varas de Família, Vara de Execuções criminais, de Violência doméstica e intrafamiliar), bem como com os projetos extrajudiciais desenvolvidos em parceria com a sociedade civil, entre outros aqui não denominados.

Nessa senda, relembrando que as normativas internacionais indicam aos países signatários a implementação da Justiça restaurativa nos seus ordenamentos jurídicos, bem como a sua característica multidimensional se trabalhar com os conflitos (a mediação, a conciliação e as suas práticas restaurativas propriamente ditas e reconhecidas como: mediação vítima-ofensor, círculos de construção de paz, câmaras restaurativas) acredita-se na Resolução CST (Conselho da Justiça do Trabalho) n. 174, de 30 de setembro de 216 que, dispõe sobre a política judiciária nacional de tratamento adequado das disputas de interesses 
no âmbito do Poder Judiciário Trabalhista e nas Comissões de Conciliação Prévia , no art. 625-D da CLT como espaços a ser reinventados para operacionalidade de soluções compartilhadas de conflitos trabalhistas extrajudicialmente e judicialmente, como sendo uma via distinta para a promoção dos direitos humanos, do Acesso à justiça via dos direitos sociais , da cidadania da inclusão social e da paz social com dignidade.

Contextualizando ainda, verificar se com a Reforma trabalhista $13.467 / 17$ pode-se avançar essas discussões ou, por conta dela, o Acesso à Justiça via dos direitos sociais está em declínio e com efeito, retrocesso as políticas judiciárias de tratamento adequado das disputas de interesse no âmbito do Poder Judiciário Trabalhista, inviabilizando a implementação da Justiça restaurativa.

Justifica-se a relevância do referido artigo por conta do seguinte problema: Considerando o panorama dos direitos humanos, o Acesso à justiça pela via dos direitos sociais; Considerando a análise do marco teórico nacional e internacional sobre a Justiça restaurativa fora do âmbito trabalhista; Considerando a observância da Resolução CSJT $n^{\circ}$ 174, de 30 de setembro de 2016 que dispõe sobre a política judiciária nacional de tratamento adequado das disputas de interesses no âmbito do Poder Judiciário Trabalhista, bem como a lei 13.467/17 que versa sobre a Reforma Trabalhista, pergunta-se: atualmente é possível implementar a Justiça Restaurativa nos conflitos individuais e coletivos de trabalho? Quais os limites e as possibilidades?

\section{Direitos Humanos e Acesso à Justiça}

A ideia de Direitos Humanos parece para a grande maioria, totalmente certa e esgotada, sem haver a necessidade de se discutir questões que envolvam esse tema. Porém, muito se engana, quem considera que esta fala esteja neutra e sem questões que necessitam ser levadas em consideração, e principalmente, à debate, pois existe um problema enorme, na fundamentação teórica do discurso que domina os debates sobre direitos humanos, o qual, exerce grande influência o período da colonialidade, fazendo com que não se possa exercitar novos discursos, principalmente àqueles que dizem respeito ao de povos esquecidos, oprimidos e principalmente, silenciados. Assim, importante é fazer uma análise, sobre o tema, 
a partir de um pensamento descolonial e que permita-se uma nova visão sobre direitos humanos (BRAGATO, 2014).

Para a grande maioria, como mencionado por Fernanda Frizzo Bragato (2014), os direitos humanos são frutos de um projeto moral, jurídico e político que foi criado e teve sua origem no Ocidente, na qual só mais tarde, quando já amadurecido, passa a se desenvolver e propagar no resto do mundo. Tal fato, acaba por trazer algumas "raízes" dos direitos humanos e para muitos, não consegue ser efetivado da melhor forma possível. Sabe-se que com o passar dos anos, cada vez mais têm-se ferramentas que garantem a aplicabilidade dos direitos humanos à todos os cidadãos, mas difícil muitas vezes, é que todos de fato tenham acesso à essas ferramentas. Assim, vêm de encontro também, o direito humano básico de Acesso à Justiça, o qual, quando devidamente garantido, traz inúmeros benefícios, pois, se violado algum outro direito, com este se é possível buscar a eficácia de todos os demais.

Em outras palavras, o acesso à justiça é um direito fundamental de todo o cidadão que busca dentro do seu Estado e da sua sociedade respaldo jurídico para assegurar a proteção e as garantias dos seus direitos. Abordar sobre este direito não é tarefa simples, no atual cenário político, econômico e jurídico brasileiro. Porém, é relevante tratar e relembrar o quanto ter reconhecido como um direito fundamental a pessoa representou uma conquista, pois algumas barreiras foram ultrapassadas.

Desse modo, pode-se dizer que este é um direito constitucionalmente garantido, podendo ser classificado como um direito fundamental de todo cidadão. Para muitos, o acesso à justiça é o direito humano mais básico e imprescindível, pois é por meio dele que se busca a garantia plena dos demais direitos. A Constituição Federal de 1988 em seu artigo $5^{\circ}$ traz consagrado este direito, afirmando que toda e qualquer pessoa possa ter garantia de resolução quando um direito seu for violado ou ameaçado. Sendo assim, “o acesso à justiça pode ser encarado como o requisito fundamental - o mais básico dos direitos humanos - de um sistema jurídico moderno e igualitário que pretenda garantir, e não apenas proclamar os direitos de todos." (CAPPELLETTI, 2017, p. 14)

Este direito pode ser conceituado de várias formas. A mais tradicional é que todos têm direito a provocar o Poder Judiciário no caso de ter violado/ameaçado um direito seu, mas atualmente, com toda evolução histórica e social, o acesso à Justiça vai muito além, uma vez que abrange todo e qualquer meio de solução de conflitos eficaz, célere a satisfatório, se tornando este, o conceito mais aceito nos dias atuais. 
Outrossim, é inegável que a crise do Judiciário decorre da crise do Estado contemporâneo, que não tem mais condições de solucionar todos os conflitos existentes na sociedade. Inúmeros são os problemas enfrentados pelo Judiciário de vários países e as soluções encontradas têm se mostrado insuficientes e inadequadas. (AMARAL, 2009)

A incidência de conflitos está aumentando visivelmente na sociedade. De um lado, por falta de tempo as pessoas estão se tornando individualistas, deixando de dialogar com os outros, além da perda dos laços de solidariedade, o que gera uma incompreensão entre os indivíduos. De outro lado, a sociedade vivencia novos conflitos, em decorrência das transformações sociais, econômicas e políticas, do crescimento excessivo da população urbana, da industrialização, do grande contingente de desempregados, do surgimento de novas tecnologias, do elevado índice de violência, fazendo com que os conflitos tenham alto grau de complexidade.

O sistema judicial de muitos países latino-americanos, como europeus, africanos e asiáticos passaram por reformas, se tornando protagonistas do contexto sócio jurídico. No entanto, mesmo com a criação de outras políticas de gestão, como no caso do Brasil que criou o Conselho Nacional de Justiça (CNJ), para modernizar o Judiciário e se tornar uma justiça de proximidade, dialogando com a comunidade e qualificando a sua prestação de serviço, ainda carece de modernidade, eficácia e eficiência nas suas políticas públicas de tratamento de conflitos.

Segundo Santos, o protagonismo dos tribunais emerge desta mudança política havendo a necessidade de ruptura do neoliberalismo europeu para o liberalismo americano. Entre outras circunstâncias, mister um Judiciário eficaz, rápido e independente. Nesse contexto de necessárias mudanças, está a precarização dos direitos econômicos e sociais passando a ser um motivo de procura do Judiciário. "O que significa que a litigância tem a ver com culturas jurídicas e políticas, mas tem a ver, também, com um nível de efetividade da aplicação dos direitos e com a existência de estruturas administrativas que sustentam essa aplicação." (SANTOS, 2007, p. 17).

De outra banda, pode-se dizer que a crise do Judiciário é decorrente de uma crise maior, a crise do Estado contemporâneo, aliada à crise do Direito e do processo, pois não funciona mais o sistema processual tradicional, com a morosidade da prestação jurisdicional, com o seu formalismo exacerbado, oriundo do positivismo jurídico. Embora as diversas medidas adotadas pelo Judiciário no sentido de solucionar os problemas apresentados, elas 
ainda são insuficientes. Contudo, o Judiciário brasileiro está acompanhando o movimento de reformas adotadas por outros países, visando solucionar os obstáculos que inviabilizam o acesso à justiça (AMARAL, 2009, p. 49).

Sabe-se que o conflito é bastante comum entre os seres humanos, tendo em vista a disputa pelos bens da vida, sendo poucos os bens e muitos os interesses. Há três diferentes formas de se obter a solução de um conflito de interesses: autotutela (ou autodefesa), autocomposição e heterocomposição. A autotutela é a solução violenta do conflito, na qual os litigantes tentam impor sua pretensão através da força. A autocomposição é a solução pacífica do conflito de interesses por meio dos próprios interessados e muitas vezes mediante a contribuição de um terceiro. Por fim, a heterocomposição ocorre quando a solução do litígio é atribuída exclusivamente a terceiros, estranhos ao objeto da controvérsia.

Não se pode perder de vista, também, que o aparato judicial, para tratar os conflitos atuais, serve-se de instrumentos e códigos muitas vezes ultrapassados, ainda que formalmente em vigor, com acanhado alcance e eficácia reduzida. Tal eficácia e alcance muitas vezes atingem somente os conflitos interindividuais, não extrapolando o domínio privado das partes, encontrando dificuldades quando instado a tratar de direitos coletivos ou difusos (SPENGLER, 2010, p. 109).

A democratização do acesso à justiça não pode ser confundida com a mera busca pela inclusão dos segmentos sociais ao processo judicial. Antes disso, cabe conferir condições para que a população tenha conhecimento e apropriação dos seus direitos fundamentais (individuais e coletivos) e sociais para sua inclusão nos serviços públicos de educação, saúde, assistência social, etc., bem como para melhor harmonização da convivência social.

$\mathrm{O}$ acesso à justiça pode, portanto, ser encarado como requisito fundamental - o mais básico dos direitos humanos - de um sistema jurídico moderno e igualitário que pretenda garantir, e não apenas proclamar os direitos de todos.

A ineficiência na reivindicação de novos direitos ocorre pela deficiência de técnica em áreas não jurídicas, pois tais direitos exigem solução governamental para este problema, muitos grupos formaram sociedades que variam muito em tamanho e especialidades temáticas a que atendem o tipo mais comum da população em uma organização sem fins lucrativos, mantida pelo governo proporcionando aconselhamento jurídico especializado e constante supervisão em relação a interesses não representados e não organizados, crescente concepção de Justiça, basta de reducionismo na visão do servo e aplicador inerte da lei. Essa concepção 
está em conflito com um enfoque moderno do Direito e da interpretação jurídica, aliás, em geral com a teoria moderna da hermenêutica: a interpretação sempre deixa algum espaço para opções, e, portanto, para a responsabilidade.

De acordo com Santos (2007, p. 46), mister uma "revolução democrática da justiça", que exige uma outra cultura jurídica, a partir de um olhar reflexivo, que perpasse na mudança no ensino jurídico das faculdades de direito, e por efeito na formação dos magistrados e dos demais operadores jurídicos.

Mauro Cappelletti e Bryant Garth (2002, p. 11) estabeleceram uma subdivisão cronológica dos movimentos de acesso à justiça, ou seja, de tentativas de soluções para se garantir a efetividade do acesso à justiça, e cada movimento foi chamado pelos autores de "onda". A primeira "onda" teria sido a assistência judiciária; a segunda referia-se à representação jurídica para os interesses difusos, especialmente nas áreas de proteção ambiental e do consumidor e, finalmente, a terceira "onda" que seria o "enfoque de acesso à justiça", a qual compreendia os posicionamentos anteriores e tinha como objetivo enfrentar contundente e articuladamente, as barreiras ao acesso efetivo à justiça.

\section{Justiça restaurativa: compreendendo o conceito, características, princípios e valores para o diálogo social}

Como um convite ao diálogo e ao direito, a Justiça Restaurativa se deu em seus primórdios na segunda metade da década de 1970, frente a uma insatisfação proeminente do sistema de justiça criminal tradicional. Não, necessariamente, implicando a busca pelo perdão, ela se manifesta por meio de práticas restaurativas, um modelo de administração de conflitos frente a um panorama obscuro e ineficiente (ACHUTTI; PALLAMOLLA, 2014).

Adriana Goulart de Sena Orsin e Caio Augusto Souza Lara (2020, p. 3), trazem como conceito de Justiça Restaurativa aduzido pela ONU, que está

é entendida como uma aproximação, através de um processo cooperativo, que privilegia toda forma de ação, individual ou coletiva, em que as partes interessadas, na determinação da melhor solução, buscam corrigir as consequências vivenciadas por ocasião da infração, a resolução do conflito, a reparação do dano (lato senso) e a reconciliação entre as partes. 
A Justiça Restaurativa, ante a insatisfação cada vez mais veemente do tradicional sistema de justiça criminal, trouxe mudanças de paradigmas significativas, destacando-se no Brasil enquanto tratamento complementar de pacificação social de conflitos, principalmente, frente a abordagem da Resolução 2002/12 sobre "Princípios básicos a aplicação do programa de Justiça Restaurativa em Mediação Penal”, aprovada pelo Conselho Econômico e Social das Nações Unidas, em abril de 2002.

A resolução, dado seu caráter pragmático, carece de força vinculante, contudo é de suma importância visto que proclama a justiça reparadora em todas as fases do processo da justiça criminal, possibilitando ao ofensor, inclusive, a reflexão quanto a seus erros e a reparação do dano ao ofendido, bem como reparação do dano a comunidade. (DA CRUZ, 2016). Ademais, insta os Estados membros a utilização destes programas de justiça reparadora, comprometendo diversas autoridades ao efetivo desta cultura restaurativa.

Referindo-se explicitamente à "mediação", à “conciliação" e à “conversas e reuniões para decidir condenações", a resolução - com uma terminologia inequivocamente angloamericana- traça a definição do "processo reparador", bem mais do que o conceito da própria justiça reparadora, preconizando que este espelho de justiça "promove a harmonia social mediante a recuperação das vítimas, dos delinquentes e das comunidades" (ONU, 2020, p. 2). Contudo, mister ressaltar que a resolução não possui uma aplicação obrigatória pelos magistrados, tratando-se de orientações para aqueles que desejam sua efetivação no âmbito judiciário.

\footnotetext{
Apesar da boa redação da Resolução n. 2002/12 da ONU, o legalismo característico da cultura jurídica brasileira indica que a presença de uma lei que regulamente a justiça restaurativa no Brasil (ou que funcione como um referencial de organização) pode colaborar significativamente senão para o avanço do tema, pelo menos para uma mais ampla discussão a seu respeito. (ACHUTTI; PALLAMOLLA, 2014, p. 449)
}

A expressão "Justiça Restaurativa” é uma criação atribuída a Albert Eglash, utilizada pela primeira vez enquanto "Justiça Reparadora" na seara criminal. O autor do artigo intitulado "Beyond Restitution: Creative Restitution, sugeriu uma tipologia tripla de justiça criminal: “(1) a justiça retributiva, baseada na punição; (2) a justiça distributiva, baseada no tratamento terapêutico de delinquentes; e (3) a justiça restaurativa, baseada na restituição". (VAN NESS; STRONG, 2010, p. 21) 
O instituto por ora estudado - diferentemente dos modelos tradicionais de punição traz seu foco nos efeitos nocivos das ações dos criminosos, envolvendo ativamente vítimas e agressores no processo de reparação e reabilitação. Ao contrário, estão os modelos de punição que orbitam nas ações dos criminosos, negando a participação da vítima no processo de justiça, e requerendo a participação meramente passiva do criminoso. (VAN NESS; STRONG, 2010, p. 21-22)

Ainda, a Justiça Restaurativa traz como intuito olhar para o futuro, restaurando os relacionamentos e não olhar para o passado e fatos que já se foram. Assim, ela "será capaz de preencher as necessidades emocionais e de relacionamento, além de ser um dos elementos para o desenvolvimento de uma cultura voltada à paz social.” (ORSINI; LARA, 2020, p. 4)

Nesta seara, Santana (2007, p. 55) nos ensina que a Justiça Restaurativa aduz a uma denotação mais humana e participativa, com desígnio primordial de encontrar a paz. Trata-se de um " processo por el cual todas las partes que tienen um interés em uma determinada ofensa se jutan para resolverla colectivamente y para tratar sus implicaciones de futuro."

Para Mera Gonzalez-Ballesteros (2020, p. 183) é notável a posição oposta de um acusado em processo de Justiça Restaurativa em comparação ao acusado que enfrenta um processo criminal tradicional. A Justiça Restaurativa busca uma solução de conflitos, com possibilidade de discussão, mas de maneira satisfatória, desvinculando a orientação para a prova de fatos.

O instituto de longe pode ser considerada um movimento unívoco, mas sim um movimento flexível. Os círculos - por suas variedades práticas de programas - podem ser adaptados a diferentes culturas, bem como aos interesses e valores distintos de seus povos.

Ruggiero APUD Achutti (2014, p. 60) nos ensina que a justiça restaurativa não apresenta vencedores nem perdedores "mas busca apenas a satisfação das necessidades básicas das partes, de modo a proporcionar uma decisão em que os interesses de todos possam ser contemplados." Ao se cogitar em amplitude essa palavra "todos", podemos incluir neste roll, além do ofensor e da vítima, a própria sociedade, enquanto interessada na situação. (ZEHR, 2008, p. 257)

Frente a violência que tem mobilizado a sociedade contemporânea e diante à insuficiência do sistema atual em lidar com as diversas complexidades do crime, a Justiça Restaurativa intenta uma fuga ao paradigma tradicional crime-castigo, buscando uma solução de conflitos mais célere, informal, participativa e com respostas mais consentâneas ao estado 
democrático de direto, bem como com a dignidade da pessoa humana. Só o fato de o ofensor consentir em participar de um processo restaurativo já retira a força do braço pesado do Estado, diminuindo riscos de abusos, fortalecendo garantias. (MERA GONZALEZBALLESTEROS, 2020)

Nesta seara, a partir da análise da Resolução $n^{\circ} 125$ do CNJ, fala-se de Justiça Restaurativa interligada com a proposta de mediação e da conciliação. A primeira, mais utilizada, consiste no encontro vítima-ofensor objetivando um acordo reparador, apoiadas por um profissional denominado mediador, que atua de forma neutra, sem interferência. Quanto a conciliação, existe a presença do conciliador em uma prática de autocomposição, escutando as partes e atuando como um facilitador para a tomada de decisão. Na própria resolução por ora mencionada, estão presentes os critérios que o conciliador deve observar, quais sejam da “confidencialidade, decisão informada, competência, imparcialidade, independência e autonomia, respeito à ordem pública e às leis vigentes".

Ainda, no que tange à Justiça Restaurativa, Orsini e Lara (2020, p. 5), mencionam que a carta produzida na Conferência Internacional "Acesso à Justiça por Meios Alternativos de Resolução de Conflitos” ocorrida em Brasília no ano de 2005, elenca dezoito princípios e valores dos procedimentos restaurativos, os quais mencionam ser:

1. plenas e precedentes informações sobre as práticas restaurativas e os procedimentos em que se envolverão os participantes; 2 . autonomia e voluntariedade na participação em práticas restaurativas, em todas as suas fases; 3. respeito mútuo entre os participantes do encontro; 4. co-responsabilidade ativa dos participantes; 5. atenção às pessoas envolvidas no conflito com atendimento às suas necessidades e possibilidades; 6. envolvimento da comunidade, pautada pelos princípios da solidariedade e cooperação; 7. interdisciplinariedade da intervenção; 8. atenção às diferenças e peculiaridades sócio-econômicas e culturais entre os participantes e a comunidade, com respeito à diversidade; 9. garantia irrestrita dos direitos humanos e do direito à dignidade dos participantes; 10. promoção de relações equânimes e não hierárquicas; 11. expressão participativa sob a égide do Estado Democrático de Direito; 12. facilitação feita por pessoas devidamente capacitadas em procedimentos restaurativos; 13. direito ao sigilo e confidencialidade de todas as informações referentes ao processo restaurativo; 14. integração com a rede de políticas sociais em todos os níveis da federação; 15. desenvolvimento de políticas públicas integradas; 16. interação com o sistema de justiça, sem prejuízo do desenvolvimento de práticas com base comunitária; 17. promoção da transformação de padrões culturais e a inserção social das pessoas envolvidas; 18. monitoramento e avaliação contínua das práticas na perspectiva do interesse dos usuários.

Outrossim, pode-se se destacar também que as práticas restaurativas possuem cinco diretrizes centrais, para conduzir a sua melhor prática, dentre as quais cita-se de forma sucinta, que é dar aos danos causados prioridades em relação às regras formais, mostrar 
preocupação igual, tanto com agressor e vítima, sem polarizar, trabalhar na reparação do dano, apoiando as vítimas, as famílias e também a comunidade afetada, apoiar o infrator, fazendo-o compreender a necessidade de cumprir com suas obrigações e tentar fazer o agressor entender que as obrigações não são impossíveis de serem cumpridas e que tentarão ao máximo reestabelecer o status quo ante ao cometimento da agressão (ORSINI; LARA, 2020).

Desta feita, percebe-se a difusão da Justiça Restaurativa no Brasil a partir da Resolução $n^{\circ} 225$ do CNJ/2016, observando-se as orientações da ONU na busca de meios eficazes ao alcance da pacificação de conflitos, resgatando as relações humanas desgastadas por crimes e violência, propondo uma análise acentuada das emoções dos envolvidos, na busca da conscientização do dano causado.

É importante destacar que os limites da própria justiça tradicional frente a Justiça Restaurativa não devem ser dispensados, mas talvez remodelados, bem como esta, pode ser aplicada em várias áreas, não apenas na ceara criminal, mas em todas àquelas que necessário e aplicável for, o diálogo e a compreensão mútua. A base internacional de direitos humanos pode direcionar um caminho para determinados questionamentos e até trazer uma padronização acerca da matéria. Contudo, a forma como estes instrumentos internacionais de humanização deve, em suas especificidades, conduzir e processar a Justiça Restaurativa, continuam a desvelar obstáculos. (MERA GONZALEZ-BALLESTEROS, 2020, p. 182-183)

\section{As práticas restaurativas na Justiça do Trabalho: Limites e Possibilidades}

A Justiça do Trabalho tem como um de seus princípios o da celeridade e vinculado a este princípio tem-se o princípio da proteção do trabalhador e da imediatidade no que tange a resposta rápida e eficaz aos que labutam e buscam nela o reconhecimento dos seus direitos sociais pela via do acesso à justiça. Por conta disso, e bem como em sintonia com a forma alternativa de acesso a justiça -, a mediação, recepcionada pela Resolução 125 de 2010 e editada pelo Conselho Nacional de Justiça (CNJ); o Conselho Superior da Justiça do Trabalho (CSJT) também editou no dia 30 de setembro de 2016 a Resolução no 174, que dispõe sobre a Política Judiciária Nacional de Tratamento Adequado das Disputas de Interesses no âmbito do Poder Judiciário Trabalhista. Sendo esta uma resposta ao Anexo 2 da Resolução 125 do CNJ. 
O NUPEMEC (Núcleo Permanente de Métodos Consensuais de Solução de Conflitos) como preceitua a Resolução CSJT 174/16, tem várias atribuições, entre elas se destacam, promover, incentivar e fomentar a investigação, estudos e o aperfeiçoamento dos métodos de mediação e conciliação individuais e coletivos. Assim como as práticas de gestão de conflitos; incentivar e promover a capacitação e o enfrentamento e a atualização permanente dos magistrados e os servidores sobre os métodos consensuados de solução de conflitos. Além disso:

\begin{abstract}
La coordinación del NUPEMEC-JT es ejercida, privativamente, por uno o más magistrados de la activa, indicados por el presidente del respectivo TRT sobre la base de criterios objetivos, pudiendo haber acumulación con la coordinación del CEJUSC-JT, quedando a cargo de la presidencia del TRT el análisis de la conveniencia y oportunidad de la designación exclusiva de magistrados para tales actividades, según el artículo 5, § 2, de la Resolución CSJT 174/2016. A su vez, el CEJUSC-JT es una unidad vinculada al NUPEMEC-JT y coordenada por un magistrado de la activa, según el artículo 6, caput y § 2, de la Resolución CSJT 174/2016. El juez coordinador podrá ser auxiliado por jueces supervisores, los cuales, además de supervisar las actividades de los mediadores y conciliadores, son responsables de homologar los acuerdos entablados (artículos 5, § 2, y 7, caput, de la Resolución CSJT 174/2016). (SPENGLER; DA COSTA, 2019, p. 53)
\end{abstract}

É sabido que os conflitos de interesses são predominantemente resolvidos através das reclamações trabalhistas na Justiça do Trabalho. Cerca de metade delas terminam em conciliação na primeira audiência. "Para a outra metade dos conflitos, a solução vem normalmente pela sentença, ato pelo qual o Juiz decide a lide, em nome do Estado, entre as partes que se apresentaram no processo.” (ORSINI; LARA, 2020, p. 12)

Segundo Viana (2002), APUD Orsini e Lara (2020), acreditava-se que as Comissões de Conciliação Prévia (CCPs), poderiam ser grandes espaços para a resolução do conflito laboral. Entretanto, foram relatados alguns problemas graves e várias distorções nos trabalhos desenvolvidos por essas comissões, “como fraudes aos direitos trabalhistas, acordos sem critérios e com eficácia liberatória geral, além do esvaziamento da função sindical efetiva e da flexibilização dos direitos trabalhistas" (VIANA, 2002 APUD ORSINI; LARA, 2020, p. 12).

Conforme Orsini e Lara (2020, p. 12) destacam que, o Supremo Tribunal Federal contribuiu para o enfraquecimento das CCPs,

ao conferir decisão liminar nas ADIs 2139 e 2160, em maio de 2009, para dar interpretação conforme a Constituição Federal ao artigo 625-D da CLT, que obrigava o trabalhador a primeiro procurar a conciliação no caso de a demanda trabalhista ocorrer em local que conte com uma comissão de conciliação, seja na 
empresa ou no sindicato da categoria. O fundamento da referida decisão é de que o 625-D da CLT impede o acesso universal à Justiça. Deste modo, esse órgão perdeu sua força extrajudicial de conciliação que resolveria mais rapidamente o litígio e desafogaria o Judiciário Trabalhista.

Ainda, outra iniciativa que merece destaque como forma de aplicação de um sistema de resolução de conflitos na ceara trabalhista, trata-se do Núcleo Intersindical de Conciliação Trabalhista - NINTER, o qual foi implantado de 1994, no Estado de Minas Gerais, Município de Patrocínio. Por meio da aplicação desse projeto, foram reduzidas as demandas judiciais trabalhistas naquele município, em cerca de $80 \%$ e a redução de informalidade, a qual tinha taxa de $80 \%$, caiu para apenas $20 \%$. (ORSINI; LARA, 2020)

Esse sistema, leva muito em consideração também, as iniciativas de mediação realizadas pelo MPT e MTE, Termos de Ajustamento de Condutas, Acordos e Convenções Coletivas e todas as demais formas de resolução de conflitos trabalhista. Ainda, importante mencionar que ele é baseado em alguns princípios constitucionais, dentre os quais o "da autonomia coletiva, da negociação coletiva, nos princípios da paridade, do tripartismo de base, do diálogo social, da interatividade das instituições do trabalho (coletivas e do poder público), dentre outros.”(ORSINI; LARA, 2020, p. 12-13)

Sendo assim, a Justiça do Trabalho tem um grande potencial para utilização das práticas restaurativas nos conflitos trabalhistas, "pelo uso efetivo da conciliação nas audiências de sua alçada" (ORSINI; LARA, 2020, p. 13). Orsini e Lara (2020), sugerem que em alguns conflitos trabalhistas como em casos de acidente de trabalho, trabalho infantil e trabalho análogo ao de escravo, os procedimentos restaurativos como, a escuta restaurativa, o debate restaurativo, a mediação restaurativa, a mediação vítima-transgressor, os círculos restaurativos, as câmaras restaurativas e as câmaras de família, poderiam funcionar tanto no âmbito das Comissões de Conciliação Prévia e do NINTER, quanto em Núcleos de Restauração da Justiça do Trabalho.

A utilização desses espaços com as práticas restaurativas, incluindo ainda, de maneira extrajudicial a mediação e a conciliação poderiam colaborar na redução dos conflitos trabalhistas, bem como serviria para a Justiça do Trabalho efetivar a política pública preceituada na Resolução 174 do CSJT.

Para melhor compreensão, interessante a seguinte análise: 


\begin{abstract}
Ajuizada a reclamação trabalhista, o juiz, se não logrado êxito a conciliação tem dois caminhos judiciais e legais: determinar a reintegração do trabalhador injustamente dispensado ou aplicar a sanção do art. 496 da CLT. Repita-se frustrado o acordo, o juiz tem que tomar uma decisão verdadeiramente difícil, que tem o risco de submeter uma pessoa a voltar ao trabalho num ambiente hostil ou até mesmo de deixar um trabalhador apto e com vontade de trabalhar em sua residência, além de determinar o pagamento de direitos integrais a uma empresa que poderia, muito receber a força de trabalho do empregado, em efetiva reintegração e higidez do contrato de trabalho. Nessa zona cinzenta, o círculo restaurativo, através da abordagem interdisciplinar (com o auxílio dos psicólogos judiciais e assistentes sociais judiciais) e do diálogo franco sem a procura de culpados, poderia ser oferecido pelo juiz às partes, que de comum acordo - elemento essencial no processo restaurativo - aceitariam a suspensão do processo para que o círculo acontecesse. Assim, o método restaurativo poderia contribuir para o esclarecimento da situação fática ali apresentada, facilitar a superação da questão emocional que impediria a volta do empregado e favorecer a continuidade da relação de emprego. Neste ponto, é salutar a lembrança de que o princípio da continuidade da relação de emprego é dos princípios mais importantes de Direito do Trabalho. (ORSINI; LARA, 2020, p. 15)
\end{abstract}

Nessa perspectiva as práticas restaurativas poderiam ser uma via de acesso à justiça ao trabalhador, pois asseguraria uma escuta qualitativa e o empoderamento do trabalhador nos espaços de trabalho. Com isso, diminuiria as consequências dos danos emocionais e consequentemente por muitas vezes, o próprio desemprego, garantindo uma maior aplicabilidade de direitos básicos do trabalhador.

\title{
CONSIDERAÇÕES FINAIS
}

Com base em todos os fatos mencionados, pode-se concluir que, o acesso à justiça é um direito fundamental de todo o cidadão que busca dentro do seu Estado e da sua sociedade respaldo jurídico para assegurar a proteção e as garantias dos seus direitos. Ainda, pode-se dizer que este é um direito constitucionalmente garantido, podendo ser classificado como um direito fundamental de todo cidadão. Para muitos, o acesso à justiça é o direito humano mais básico e imprescindível, pois é por meio dele que se busca a garantia plena dos demais direitos.

Desse modo, o acesso à justiça pode, portanto, ser encarado como requisito fundamental - o mais básico dos direitos humanos - de um sistema jurídico moderno e igualitário que pretenda garantir, e não apenas proclamar os direitos de todos.

Assim, a partir da análise da Justiça Restaurativa como forma de resolução de conflitos, propriamente dita, é possível concluir que a expressão "Justiça Restaurativa" é uma 
criação atribuída a Albert Eglash, utilizada pela primeira vez enquanto "Justiça Reparadora" na seara criminal. O autor do artigo intitulado "Beyond Restitution: Creative Restitution, sugeriu uma tipologia tripla de justiça criminal, como a justiça retributiva, baseada na punição; a justiça distributiva, baseada no tratamento terapêutico de delinquentes; e a justiça restaurativa, baseada na restituição.

Esse instituto traz seu foco nos efeitos nocivos das ações dos criminosos, envolvendo ativamente vítimas e agressores no processo de reparação e reabilitação. Ainda, a Justiça Restaurativa traz como intuito olhar para o futuro, restaurando os relacionamentos e não olhar para o passado e fatos que já se foram. Assim, ela vai ser capaz de preencher as necessidades emocionais e de relacionamento, além de ser um dos elementos para o desenvolvimento de uma cultura voltada à paz social.

Já, no que tange à Justiça Restaurativa aplicada na Justiça do Trabalho, esta tem como um de seus princípios o da celeridade e vinculado este princípio tem-se o princípio da proteção do trabalhador e no que tange a resposta rápida e eficaz aos que labutam e buscam nela o reconhecimento dos seus direitos sociais pela via do acesso à justiça. Por conta disso, e bem como em sintonia com a forma alternativa de acesso a justiça -,o Conselho Superior da Justiça do Trabalho (CSJT) editou no dia 30 de setembro de 2016 a Resolução n ${ }^{\circ}$ 174, que dispõe sobre a Política Judiciária Nacional de Tratamento Adequado das Disputas de Interesses no âmbito do Poder Judiciário Trabalhista.

Sendo assim, a Justiça do Trabalho tem um grande potencial para utilização das práticas restaurativas nos conflitos trabalhistas e só traz benefícios em sua aplicação.

Por fim, respondendo aos questionamentos apresentados como problema central da pesquisa, que foram analisar se atualmente é possível implementar a Justiça Restaurativa nos conflitos individuais e coletivos de trabalho e quais os limites e as possibilidades dessa aplicação, pode-se dizer que a resposta é afirmativa, ou seja, é possível sim aplicação dessa forma de resolução de conflitos na Justiça do Trabalho e inclusive traria inúmeros benefícios ao trabalhador, como garantia de aplicação de direitos humanos básicos.

\section{REFERÊNCIAS BIBLIOGRÁFICAS}

ACHUTTI, Daniel; PALLAMOLLA, Rafaela. Justiça Restaurativa. Segurança Pública. In.: LIMA, Renato Sérgio; RATTON, Luiz; GHINGHELLI, Rodrigo (Orgs.). Crime, Policia e justiça no Brasil. São Paulo: Contexto, 2014, p. 436-449 
ACHUTTI, Daniel. Abolicionismo penal e justiça restaurativa: do idealismo ao realismo político-criminal. R. Dir. Gar. Fund., Vitória, v. 15, n. 1, p. 33-69, jan./jun. 2014.

AMARAL, Márcia Terezinha Gomes. O Direito de acesso à justiça e a mediação. Rio de Janeiro: Lumen Juris, 2009.

BRAGATO, Fernanda Frizzo. PARA ALÉM DO DISCURSO EUROCÊNTRICO DOS DIREITOS HUMANOS: CONTRIBUIÇÕES DA DESCOLONIALIDADE. In: Revista Novos Estudos Jurídicos - Eletrônica, vol. 19 - n. 1 - jan-abr 2014 - p.201-230.

BRASIL. CONSELHO NACIONAL DE JUSTIÇA (CNJ). Resolução n. ${ }^{\circ} 225$ de 31 de maio de 2016. Diário Oficial [da] República Federativa do Brasil, Brasília, DF, 1 abr. 2016. Disponível em: <http://www.cnj.jus.br/images/atos_normativos /resolucao/resolucao_ 225_31052016_02062016161414.pdf>. Acesso em 10 abr. 2020

CAPPELlETTI, Maria de Lemos Queiroz. FORMULAÇÃO DE POLÍTICAS PÚBLICAS NO ÂMBITO DO CONSELHO NACIONAL DE JUSTIÇA: a mediação e a conciliação como instrumentos adequados de solução de conflitos. Paraíba: UEPB, 2017, 67 p. Monografia - Curso de Especialização em Prática Judicante, Universidade Estadual da Paraíba, UEPB, Paraíba, 2017.

CAPPELLETTI, Mauro; GARTH, Bryant. Acesso à justiça. Tradução de Ellem Gracie Northfleet. Porto Alegre: Fabris, 2002.

DA CRUZ, Fabrício Bittencourt. Justiça restaurativa: horizontes a partir da Resolução CNJ 225. Brasília: CNJ, 2016, 388 p.

MERA GONZALEZ-BALLESTEROS, Alejandra. Justicia Restaurativa Y Proceso Penal Garantías Procesales: Límites Y Posibilidades. Ius et Praxis, Talca, v. 15, n. 2, p. 165-195, 2009. Disponível em: <https://scielo.conicyt.cl/scielo.php?script=sci_arttext\&pid=S071800122009000200006\&lng=en\&nrm=iso\&tlng=en>. Acesso em: 30 abr. 2020.

ORSINI, Adriana Goulart de Sena; LARA, Caio Augusto Souza. A justiça restaurativa: uma abrangente forma de tratamento de conflitos. Disponível em: <file:///C:/Users/user/Downloads/adriana_sena_justica_restaurativaJUSTI\%C3\%87A\%20NO \%20DIREITO\%20DO\%20TRABALHO.pdf.>. Acesso em 02 abr. 2020.

ONU, Organização Das Nações Unidas. Resolução n. ${ }^{\circ}$ 2002/12 da ONU - princípios básicos para utilização de programas de justiça restaurativa em matéria criminal. Disponível em: <http://www.juridica.mppr.mp.br/arquivos/File/ MPRestaurativoEACulturadePaz/Material _de_Apoio/Resolucao_ONU_2002.pdf>. Acesso em: 20 abr. 2020.

SANTANA, Luis F. Gordillo. La Justicia Restaurativa y La Mediación Penal. Madrid: Paracuellos de Jarama, 2007.

SANTOS, Boaventura de Souza. Para uma revolução democrática da justiça. São Paulo: Cortez, 2007, v. 134. 
SPENGLER, Fabiana Marion; DA COSTA, Márcio Dutra. Mediación procesal de conflictos colectivos en la justicia del trabajo brasileña. In: REVISTA CHILENA DE DERECHO DEL TRABAJO Y DE LA SEGURIDAD SOCIAL VOL. 10 NÚM. 19, 2019, PÁGS. 4162.

SPENGLER, Fabiana Marion. Da jurisdição à mediação: por uma outra cultura no tratamento dos conflitos. Ijuí: Unijuí, 2010.

VAN NESS, D. W.; STRONG, K. H. Restoring Justice: an introduction to Restorative Justice. New Providence: Matthew Bender \& Company, 2010.

ZEHR, HOWARD. Trocando as lentes. Um novo foco sobre o crime e a justiça. Tradução de Tônia Van Acker. São Paulo: Palas Athena, 2008. 